\title{
Is your love in vain? On associations between genotypes, drug concentrations and clinical outcomes in pharmacogenomic research
}

\author{
Per Damkier $^{1}$ (D)
}

Received: 29 June 2015/ Accepted: 9 July 2015 / Published online: 17 July 2015

(C) Koninklijke Nederlandse Maatschappij ter bevordering der Pharmacie 2015

In this issue of IJCP, Chawla et al. [1] report on an association between CYP2C19 genotype and plasma voriconazole levels. Based on retrospective data on voriconazole dose, plasma concentration levels, and CYP2C19 genotypes in 55 patients, the authors conclude, "...voriconazole monitoring and genotype analysis may assist in clinical practice and better patient care", and suggest impact on clinical practice: "CYP2C19 genotype and voriconazole monitoring at initiation...... is required to achieve therapeutic targets".

The authors are applauded for their efforts within a complex area of research. However, while the study is certainly of interest and adds value to our knowledge and scientific understanding of the subject at hand, the conclusions on clinical relevance by the authors are in my view not supported by their results to a reasonable extent. By correction for dose no statistically significant inference was found for the vast majority of the study population heterozygous to the variation studied. The statistically significant result notwithstanding, the predictive value for those four patients homozygous to the CYP2C19*2 variant allele is not convincingly demonstrated. I believe that the inference made to better patient care is perhaps too speculative and holds little scientific justification from the study results [1].

Chawla and co-authors are certainly not alone among pharmacogenomic researchers who, perhaps in their enthusiasm and understandable excitement with own results, are tempted to draw unwarranted conclusions on clinical relevance of their research [2, 3]. Within cancer

Per Damkier

pdamkier@health.sdu.dk

1 Department of Clinical Chemistry and Pharmacology, Odense University Hospital, 5000 Odense, Denmark treatment, the pharmacogenomic approach has proven very valuable. Tumor target genomic variants are integral to decision support, or very often even explicit within the labelling, in the implementation of many new antineoplastic drugs $[4,5]$. For germ line mutations of genomic variants relevant to drug metabolism, transport and pharmacodynamics, the association between such and relevance to everyday clinical practice remain less convincing $[6,7]$. The concept of a priori specific genotyping or even an allout pre-emptive genotyping as a mean to improve health care outcome is biologically plausible, scientifically appealing and clinically satisfying [8]. These initial high hopes of improving health care outcomes though individualized therapy based on genomic knowledge are now subject to some pause and reflections within the scientific community as meaningful examples of clinically implemented pharmacogenomics outside oncology are far and few between [9-12]. Very few prospective studies have been conducted to substantiate this. This is not surprising as such gold-standard RCT approach is compromised by several factors inherent to a pharmacogenomic approach. These mainly pertain to low frequencies of specific genotype variations, functional relevance of these in terms of genotype-phenotype associations, and the order of magnitude to which such statistically significant associations translates to clinically relevant outcomes. From a strict scientific point of view documentation thereof requires complex large-scale RCTs that are prohibitively expensive as commercial interests and motivation is largely non-existent. The largest study on the most well documented association between genotype and drug dose, warfarin and VKORC1 and CYP2C9 genotypes, did find a statistically significant effect with respect to a proxy outcome, time spent within INR target range. No effect on clinical outcomes, bleedings or thrombosis, was found [13]. Even in 
this case, contradictory evidence from another clinical trial is present [14].

For most such associations between germ-line genotypes and drug dosing, RCTs to document clinical implications will remain wishful thinking [15]. In the light of this we must restrain our genuine scientific enthusiasm and excitement with results from small association studies and resist the temptation to draw unwarranted extrapolations and speculations on clinical inferences. In my opinion, overselling such study results is counterproductive, and will likely serve to alienate clinicians from embracing the concept of pharmacogenomics [11].

\section{References}

1. Chawla PK, Nanday SR, Dherai AJ, Soman R, Lokhande RV, Naik PR, Ashavaid TF. Correlation of CYP2C19 genotype with plasma voriconazole levels: a preliminary retrospective study in Indians. IJCP-D-14-00610R2.

2. Attia J, Ioannidis JP, Thakkinstian A, McEvoy M, Scott RJ, Minelli C, Thompson J, et al. How to use an article about genetic association: B: are the results of the study valid? JAMA. 2009;301:191-7.

3. Attia J, Ioannidis JP, Thakkinstian A, McEvoy M, Scott RJ, Minelli C, Thompson J, et al. How to use an article about genetic association: C: what are the results and will they help me in caring for my patients? JAMA. 2009;301:304-8.

4. Kalia M. Biomarkers for personalized oncology: recent advances and future challenges. Metabolism. 2015;64:16-21.
5. Rodríguez-Antona C, Taron M. Pharmacogenomic biomarkers for personalized cancer treatment. J Intern Med. 2015;277: 201-17.

6. Van Ness B. Applications and limitations in translating genomics to clinical practice. Transl Res. 2015. doi:10.1016/j.trsl.2015.04. 012.

7. Daly AK, Cascorbi I. Opportunities and limitations: the value of pharmacogenetics in clinical practice. Br J Clin Pharmacol. 2014;77:583-6.

8. Dunnenberger HM, Crews KR, Hoffman JM, Caudle KE, Broeckel U, Howard SC, et al. Preemptive clinical pharmacogenetics implementation: current programs in five US medical centers. Annu Rev Pharmacol Toxicol. 2015;55:89-106.

9. Janssens AC, Deverka PA. Useless until proven effective: the clinical utility of preemptive pharmacogenetic testing. Clin Pharmacol Ther. 2014;96:652-4.

10. Rubin R. Precision medicine: the future or simply politics? JAMA. 2015;313:1089-91.

11. Joyner MJ, Paneth N. Seven questions for personalized medicine. JAMA. 2015. doi:10.1001/jama.2015.7725. [Epub ahead of print] PubMed PMID: 26098474.

12. Jameson JL, Longo DL. Precision medicine-personalized, problematic, and promising. N Engl J Med. 2015;372:2229-34.

13. Pirmohamed M, Burnside G, Eriksson N, Jorgensen AL, Toh CH, Nicholson $\mathrm{T}$, et al. EU-PACT group. A randomized trial of genotype-guided dosing of warfarin. $\mathrm{N}$ Engl $\mathrm{J}$ Med. 2013;369:2294-303.

14. Kimmel SE, French B, Kasner SE, Johnson JA, Anderson JL, Gage BF, et al. COAG investigators. A pharmacogenetic versus a clinical algorithm for warfarin dosing. N Engl J Med. 2013; 369:2283-93.

15. Schork NJ. Personalized medicine: time for one-person trials. Nature. 2015;520:609-11. 